\title{
Prospective randomized double blinded comparative study on the effects of ephedrine and phenylephrine on fetal outcome and their effects on hypotension during elective cesarean section
}

\author{
R. Anitha Preethi ${ }^{1}$, A. Pushparani ${ }^{2}$ ** \\ ${ }^{1}$ Assistant Professor, ${ }^{2}$ Associate Professor, Dept. of Anaesthesia, SRM Medical College and Research Institute, Kattankulathur,
} Tamil Nadu, India

*Corresponding Author:

Email: pushpa82_dr@yahoo.com

Received: $22^{\text {nd }}$ September, 2017

Accepted: $17^{\text {th }}$ April, 2018

\begin{abstract}
Introduction: Hemodynamic instability during pregnancy may compromise the blood flow to the uteroplacental bed which may lead fetal acidosis. We compared ephedrine and phenylephrine on fetal outcome and hypotension during elective cesarean section.

Aim: To compare the effectiveness of ephedrine versus phenylephrine in fetal outcome and the treatment of fall in blood pressure during subarachnoid block for elective cesarean section.

Materials and Methods: Study Design: Prospective, randomized, double blind.

Based on inclusion and exclusion criteria 50 patients were selected and divided into two equal groups.

All patients were done under subarachnoid block as per routine in our hospital.

Group E received Ephedrine $6 \mathrm{mg}$ if $>20 \%$ fall in the heart rate and systolic blood pressure from the baseline.

Group P received phenylephrine $20 \mathrm{mcg}$ as increments if $>20 \%$ fall in the heart rate and systolic blood pressure from the baseline.

Results: Both the groups were comparable with regard to the fetal outcome (Apgar score and fetal umbilical vein ABG). Nylephrine group showed statistically significant fall in heart rate and systolic blood pressure when compared to the Ephedrine group during the first 20 minutes. After $25^{\text {th }}$ minute both the drugs were comparable.

Conclusion: Both the drugs were comparable with respect to the fetal outcome and maternal hemodynamics in patients undergoing elective cesarean section under subarachnoid block.
\end{abstract}

Keywords: Ephedrine, Phenylephrine, Hypotension, Subarachnoid block, Cesarean section.

\section{Introduction}

Maintenance of normal maternal blood pressure during spinal or epidural anesthesia avoid acidosis to the fetus and depression in the neonate. A uterine incision to delivery interval of longer than 3 minutes is associated with an increased incidence of low umbilical cord blood $\mathrm{pH}$ measurements and low Apgar scores, regardless of the anesthetic technique. ${ }^{1}$ Bader et $\mathrm{al}^{2}$ observed that a prolonged uterine incision to delivery interval is associated with a corresponding increase in umbilical artery catecholamine concentrations Measures to prevent hypotension include fluid administration prior to regional anesthesia, left uterine displacement and use of vasopressors. Ephedrine (potent $\beta$-adrenergic and a less potent $\alpha$-adrenergic agonist) is used to increase the blood pressure. It has potential complications such as tachyphylaxis, supraventricular tachycardia, and most importantly acidosis to the fetus. Phenylephrine, (an $\alpha$-adrenergic agonist) increase the blood pressure with decrease in incidence of nausea and vomiting and fetal acidosis.

In our study we compared the effectiveness of ephedrine versus phenylephrine on the fetal outcome and blood pressure in patients undergoing elective cesarean section under subarachnoid block.

\section{Objective of the Study}

1. To assess fetal outcome when either ephedrine or phenylephrine was used.

2. To study the effectiveness of bolus doses of ephedrine and phenylephrine on blood pressure and heart rate during caesarean section under subarachnoid blockade.

\section{Materials and Methods \\ Study Setting and Design}

The study was a prospective, randomized, double blind study

Blinding: First anaesthesiologist prepared the drug and drug was given and effects was monitored by second anaesthesiologists who was blinded to the study drug.

After getting ethical committee approval and informed written consent, patients were selected based on following inclusion and exclusion criteria.

\section{Inclusion Criteria:}

1. ASA physical status I and II patients

2. Age between $18-35$ years

3. posted for elective cesarean section

4. Patients giving informed, written, valid consent. 


\section{Exclusion Criteria:}

1. Patients with obstetric complications like pregnancy induced hypertension, obesity, pre existing hypertension, asthma and heart disease

2. Patients with evidence of fetal anomalies and fetal compromise

3. Patients who have contraindications for regional anesthesia

4. Any allergies to the local anesthetic or the study drug

5. ASA III and ASA IV

6. Patients on medical management like tricyclic antidepressants and MAO inhibitors

7. Randomization

Done by computer generated random numbers.

Patients were divided into two groups, (25 each).

If there is a $>20 \%$ reduction in HR or systolic blood pressure from baseline.

Group E received 6mg increments of ephedrine.

Group $P$ received $20 \mathrm{mcg}$ increments of phenylephrine.

Pre anesthetic examination was done on the previous day to surgery which also included measuring patient's height and weight, documentation of gestational age and general examination, baseline blood pressure, pulse rate, respiratory rate, mouth opening, mallampati and neck movements, systemic examination and examination of the spine for deformities.

Baseline investigations included blood routine, coagulation profile and platelet count.

All the patients were kept nil per oral for 8 hours. On the day of surgery patients were shifted to the operating room and standard monitor showing NIBP, ECG, pulse oximetry respiratory rate was attached and baseline values documented.

A $18 \mathrm{G}$ cannula was introduced into the peripheral vein and each patient was started with $15 \mathrm{ml} / \mathrm{kg}$ ringer lactate solution. Under strict aseptic precautions, local anesthesia was administered and subarachnoid block was performed at L3-L4 or L4-L5 interspace by midline approach using a $25 \mathrm{G}$ Quincke type spinal needle in sitting position. After getting free flow of cerebrospinal fluid, Bupivacaine $0.5 \% 2.2 \mathrm{ml}$ was given intrathecally. The time of injection was also noted.

A wedge was placed below the right hip to avoid supine hypotension. Heart rate and blood pressure was recorded 2 min until delivery of the baby and then every $5 \mathrm{~min}$ till $45 \mathrm{~min}$, and every $15 \mathrm{~min}$ till the end of the surgery. Loss of cold sensation for ice cubes was used to ascertain the sensory block level. Sensory block to $\mathrm{T} 4$ dermatome was considered adequate for the surgery.

Umbilical artery cord blood was sampled for estimation of acid base status of the fetus. Apgar scores for $1 \mathrm{~min}$ and $5 \mathrm{~min}$ after the delivery was documented and a score of less than 8 was considered as low.

Changes in maternal Blood Pressure (SBP, DBP, MAP), Heart Rate and Saturation were monitored and noted. Total dose of ephedrine and phenylephrine and the total volume of fluids infused were recorded along with the time of spinal anesthesia given to the delivery of the fetus and the duration of surgery was also documented.

\section{Statistical Analysis}

The observations are expressed as Mean \pm one standard deviation. The baseline hemodynamic values and the post spinal hemodynamic changes at various time intervals were compared using unpaired student ' $t$ ' tests. The $\mathrm{p}$ value $<0.05$ was considered significant.

A pilot study conducted showed mean difference in the fetal outcome (APGAR) between two groups was calculated. Power analysis was done with a beta error of 0.8 and alpha error of 0.05 and the sample size was calculated 25 in each group. $\mathrm{P}<0.05$ was considered statistically significant.

\section{Results}

In our study two groups were comparable with respect to the demography. There was no statistical significant difference ( $p$ value $>0.05$ ) between the duration of surgery, the total volume of fluid used intraoperatively and the time of sub arachnoid block to the delivery of the baby in both the groups.

No statistically significant difference among two groups with respect to Apgar scores at 1 and $5 \mathrm{~min}(\mathrm{p}$ value >0.05). No neonate had an Apgar score of $<8$ in either of the groups. No difference noted in between two groups in fetal acid base status.

The systolic and mean arterial pressures were significantly less in phenylephrine group till first 20 minutes of surgery but systolic blood pressure and heart rate were more with ephedrine group during first 20 minutes. After 20 minutes both groups have comparable hemodynamics. 
Table 1: Demography

\begin{tabular}{|l|c|c|c|c|c|c|}
\hline \multirow{2}{*}{} & \multicolumn{2}{|c|}{ Group E } & \multicolumn{2}{c|}{ Group P } & \multirow{2}{*}{ T Value } & \multirow{2}{*}{ P value } \\
\cline { 2 - 6 } & Mean & $\begin{array}{c}\text { Std } \\
\text { deviation }\end{array}$ & Mean & Std deviation & & \\
\hline Age (yrs) & 28.24 & 3.909 & 28.12 & 5.052 & 0.016 & 0.988 \\
\hline Height (cms) & 154,64 & 2.767 & 153.36 & 3.264 & 1.496 & 0.141 \\
\hline Weight (kgs) & 80.2 & 7.506 & 77.24 & 11.987 & 1.046 & 0.301 \\
\hline Gestational age (wks) & 38.668 & 0.6556 & 38.164 & 0.9246 & -2.223 & 0.031 \\
\hline Volume of the drug given & 2.2 & 0 & 2.24 & 0.0816 & 2.449 & 0.02 \\
\hline
\end{tabular}

Table 2: Statistical comparison of systolic blood pressure (SBP) among the two groups

\begin{tabular}{|l|c|c|c|c|c|}
\hline & \multicolumn{2}{|c|}{ Group E } & \multicolumn{2}{c|}{ Group P } & \multirow{2}{*}{ P value } \\
\hline & Mean & Std deviation & Mean & Std deviation & \\
\hline Base line & 122.8 & 7.789 & 128.84 & 7.278 & 0.007 \\
\hline 3 min & 81.08 & 7.637 & 93.48 & 12.981 & 0 \\
\hline $5 \mathrm{~min}$ & 95.64 & 10.424 & 85.92 & 7.112 & 0 \\
\hline $10 \mathrm{~min}$ & 138.68 & 7.149 & 90.96 & 7.027 & 0.196 \\
\hline $15 \mathrm{~min}$ & 103.92 & 7.826 & 96.96 & 8.715 & 0.005 \\
\hline $20 \mathrm{~min}$ & 105.68 & 4.437 & 98.68 & 7.487 & 0 \\
\hline $25 \mathrm{~min}$ & 106.48 & 4.584 & 103.04 & 7.469 & 0.057 \\
\hline $30 \mathrm{~min}$ & 106.88 & 4.919 & 109.8 & 4.103 & 0.027 \\
\hline $35 \mathrm{~min}$ & 108.56 & 4.814 & 110.72 & 2.542 & 0.055 \\
\hline $40 \mathrm{~min}$ & 110 & 4.688 & 111.64 & 3.439 & 0.17 \\
\hline $45 \mathrm{~min}$ & 110.84 & 4.688 & 113 & 3.617 & 0.075 \\
\hline $60 \mathrm{~min}$ & 111.54 & 3.967 & 113.68 & 3.473 & 0.051 \\
\hline $75 \mathrm{~min}$ & 112.71 & 4.101 & 124.43 & 2.89 & 0 \\
\hline $90 \mathrm{~min}$ & 113.07 & 3.792 & 112.93 & 3.54 & 0.919 \\
\hline $105 \mathrm{~min}$ & 115 & 4.163 & 115.83 & 3.43 & 0.738 \\
\hline $120 \mathrm{~min}$ & 116.33 & 4.509 & 116.5 & 2.887 & 0.955 \\
\hline
\end{tabular}

Table 3: Statistical comparison of diastolic blood pressure (DBP) among the two groups

\begin{tabular}{|c|c|c|c|c|c|c|c|}
\hline \multirow[t]{2}{*}{ Time Interval } & \multicolumn{2}{|c|}{$\begin{array}{c}\text { Group E } \\
\text { (Ephedrine) }\end{array}$} & \multicolumn{2}{|c|}{$\begin{array}{c}\text { Group P } \\
\text { (Phenylephrine) }\end{array}$} & \multirow[t]{2}{*}{ t value } & \multirow[t]{2}{*}{ p value } & \multirow[t]{2}{*}{ Significance } \\
\hline & Mean & Std Dev & Mean & Std Dev & & & \\
\hline baseline & 75.2 & 9.899 & 76.8 & 5.867 & 0.695 & 049 & No \\
\hline 3 & 51.24 & 6.24 & 56.32 & 10.892 & 2.023 & 0.049 & Yes \\
\hline 5 & 54.32 & 7.358 & 50.48 & 6.118 & -2.006 & 0.05 & Yes \\
\hline 10 & 57.48 & 7.113 & 51.72 & 5.877 & -3.121 & 0.003 & Yes \\
\hline 15 & 59.12 & 7.677 & 5564 & 8.636 & -1.506 & 0.139 & No \\
\hline 20 & 59.56 & 6.378 & 55.8 & 6.487 & -2.067 & 0.044 & Yes \\
\hline 25 & 60.4 & 6.371 & 59.28 & 6.655 & -0.608 & 0.546 & No \\
\hline 30 & 60.84 & 6.434 & 60.68 & 6.75 & -0.086 & 0.932 & No \\
\hline 35 & 60.96 & 5.87 & 61.8 & 4.453 & 0.57 & 0.571 & No \\
\hline 40 & 62.12 & 5.659 & 62.12 & 4.893 & 0 & 1 & No \\
\hline 45 & 61.68 & 6.06 & 62.52 & 4.797 & 0.543 & 0.589 & No \\
\hline 60 & 63.17 & 5.932 & 63.32 & 4.661 & 0.1 & 0.92 & No \\
\hline 75 & 62.38 & 6.682 & 64.14 & 4.757 & 0.984 & 0.331 & No \\
\hline 90 & 64.21 & 5.82 & 64.07 & 5.181 & -0.069 & 0.946 & $\mathrm{No}$ \\
\hline 105 & 67 & 10.132 & 70 & 13.216 & 0.4 & 0.706 & No \\
\hline 120 & 68.67 & 11.547 & 74.4 & 18.649 & 0.5 & 0.653 & No \\
\hline
\end{tabular}


Table 4: Statistical comparison of mean arterial pressure (MAP) among the two groups

\begin{tabular}{|c|c|c|c|c|c|c|c|}
\hline \multirow{2}{*}{$\begin{array}{c}\text { Time } \\
\text { Interval }\end{array}$} & \multicolumn{2}{|c|}{$\begin{array}{c}\text { Group E } \\
\text { (Ephedrine) }\end{array}$} & \multicolumn{2}{c}{$\begin{array}{c}\text { Group P } \\
\text { Phenylephrine) }\end{array}$} & t value & p value & Significance \\
\cline { 2 - 8 } Baseline & Mean & Std Dev & Mean & Std Dev & & & \\
\hline 3 & 90.28 & 8.744 & 90.04 & 8.218 & -100 & 0.921 & No \\
\hline 5 & 56.76 & 5.426 & 65.8 & 13.454 & 3.116 & 0.004 & Yes \\
\hline 10 & 65.32 & 7.409 & 59.8 & 6.178 & 2.861 & 0.006 & Yes \\
\hline 15 & 71.28 & 6.086 & 63.44 & 7.06 & -4.206 & 0 & Yes \\
\hline 20 & 72.68 & 5.039 & 68.56 & 8.818 & -2.208 & 0.48 & No \\
\hline 25 & 73.56 & 3.709 & 69.56 & 6.371 & -2.713 & 0.009 & Yes \\
\hline 30 & 74.56 & 3.709 & 73.4 & 6.898 & -0.741 & 0.463 & No \\
\hline 35 & 75 & 3.775 & 75.8 & 6.436 & 0.536 & 0.595 & No \\
\hline 40 & 76.12 & 3.153 & 76.56 & 5.432 & 0.35 & 0.728 & No \\
\hline 45 & 77.36 & 3.187 & 77.08 & 4.804 & -0.243 & 0.809 & No \\
\hline 60 & 77.32 & 3.614 & 78.32 & 4.625 & 0.852 & 0.399 & No \\
\hline 75 & 77.95 & 3.361 & 78.4 & 4.592 & 0.708 & 0.482 & No \\
\hline 90 & 78.64 & 2.977 & 76 & 9.414 & -1.002 & 0.326 & No \\
\hline 105 & 79.33 & 2.082 & 81.33 & 5.502 & 0.592 & 0.573 & No \\
\hline 120 & 80.67 & 2.082 & 82.75 & 3.202 & 0.972 & 0.376 & No \\
\hline
\end{tabular}

Table 5: Statistical comparison of heart rate (HR) among the two groups

\begin{tabular}{|c|c|c|c|c|c|c|c|}
\hline \multirow{2}{*}{$\begin{array}{c}\text { Time } \\
\text { Interval }\end{array}$} & \multicolumn{2}{|c|}{$\begin{array}{c}\text { Group E } \\
\text { (Ephedrine) }\end{array}$} & \multicolumn{2}{c|}{$\begin{array}{c}\text { Group P } \\
\text { (Phenylephrine) }\end{array}$} & t value & p value & Significance \\
\cline { 2 - 6 } & Mean & Std Dev & Mean & Std Dev & & & \\
\hline baseline & 89.44 & 3.698 & 96.6 & 7.059 & 4.492 & 0 & Yes \\
\hline 3 & 67.88 & 2.489 & 103.28 & 5.412 & 29.713 & 0 & Yes \\
\hline 5 & 72.16 & 4.079 & 103.24 & 10.101 & 14.266 & 0 & Yes \\
\hline 10 & 78.36 & 5.024 & 84.44 & 14.961 & 1.926 & 0.064 & No \\
\hline 15 & 84 & 6.904 & 81.36 & 12.596 & -0.919 & 0.363 & No \\
\hline 20 & 83 & 5.025 & 76.72 & 9.463 & -2.931 & 0.005 & Yes \\
\hline 25 & 83.08 & 4.271 & 79.36 & 8.445 & -1.965 & 0.055 & No \\
\hline 30 & 83.16 & 4.11 & 81.18 & 4.675 & -1.028 & 0.309 & No \\
\hline 35 & 84.04 & 3.182 & 81.52 & 5.292 & -2.04 & 0.048 & Yes \\
\hline 40 & 84.2 & 3.149 & 82.24 & 5.206 & -1.611 & 0.115 & No \\
\hline 45 & 84.2 & 2.843 & 84.04 & 4.227 & -0.154 & 0.878 & No \\
\hline 60 & 8438 & 2.516 & 83.83 & 4.743 & -0.494 & 0.623 & No \\
\hline 75 & 85.14 & 2.414 & 83.33 & 4.575 & -1.603 & 0.117 & No \\
\hline 90 & 85.07 & 2.464 & 84.5 & 5.919 & -0333 & 0.741 & No \\
\hline 105 & 85 & 1.155 & 85.33 & 9.933 & 0.065 & 0.949 & No \\
\hline 120 & 86 & 0 & 87.75 & 4.924 & 0.601 & 0.573 & No \\
\hline
\end{tabular}

Table 6: Comparison of parameters between two groups

\begin{tabular}{|l|c|c|c|c|c|c|}
\hline \multirow{2}{*}{} & \multicolumn{2}{|c|}{ Group E } & \multicolumn{2}{c|}{ Group P } & \multirow{2}{*}{ t value } & \multirow{2}{*}{ p value } \\
\cline { 2 - 6 } & Mean & Std Dev & Mean & Std Dev & & \\
\hline Time for spinal to delivery (min) & 22.44 & 7.665 & 20.96 & 7.202 & -0.704 & 0.485 \\
\hline Total fluids during surgery & 1251.25 & 139.699 & 1272.92 & 192.229 & 0.447 & 0.657 \\
\hline APGAR 1 min & 7.96 & 0.2 & 7.96 & 0.2 & 0 & 1 \\
\hline APGAR 5min & 8.92 & 0.227 & 8.96 & 0.2 & 0.586 & 0.561 \\
\hline Cord blood ABG & 7.276 & 0.01414 & 7.25 & 0.0209 & 0.1942 & 0.058 \\
\hline
\end{tabular}

\section{Discussion}

Spinal anesthesia offers the advantages of simplicity, rapid onset, and dense neural blockade. It is associated with negligible maternal risk of systemic local anesthetic toxicity, minimal transfer of drug to the infant, and negligible risk of local anesthetic depression of the infant. Spinal anaesthesia induced hypotension can be treated by volume preloading. 
Studies on volume preloading have proved that colloids are no better than crystalloids in preventing the incidence of hypotension. Colloids have certain drawbacks like:

1. Increased cost in comparison to crystalloids

2. Anaphylactic reactions

3. Interference with the clotting cascade ${ }^{1}$

4. Interference to blood grouping and cross matching studies $^{2}$

Crystalloids are required in great volumes (>15 $\mathrm{ml} / \mathrm{kg}$ ) to decrease the incidence of hypotension. ${ }^{3}$ These huge volumes have detrimental effects like:

1. Increased central venous pressure $e^{4,5}$

2. Blood dilution leading to decrease in oxygen carrying capacity

3. Release of atrial natriuretic peptide initiating diuresis, thereby attenuating the effect of volume load on blood pressure.

In due consideration prophylactic administration of a pharmacologic agent is more effective than prehydration for prevention of hypotension. ${ }^{5}$

Lee et $\mathrm{al}^{6}$ in their study reported a higher incidence of bradycardia in patients receiving phenylephrine when compared to ephedrine. They used phenylephrine in a dose of $100 \mathrm{mcg}$ in their study. But in our study, there was no bradycardia observed in patients who received phenylephrine. This can be attributed to the usage of lower doses of phenylephrine for the treatment of hypotension compared to their study.

Umbilical artery $\mathrm{pH}$ is a sensitive indicator of uteroplacental blood flow. Acidotic changes indicate severe uteroplacental insufficiency. Phenylephrine group had neonates with a higher umbilical cord $\mathrm{pH}$ (mean $=7.2858)$ than ephedrine group (mean=7.2760) but was statistically not significant. No neonate in both groups had a pH less than 7.20. Studies have confirmed the beneficial effects of phenylephrine on umbilical $\mathrm{pH}^{6,7}$

Ngan Kee et $a 1,{ }^{8}$ concluded that there were no significant differences in fetal acid-base status or in the clinical neonatal outcomes between the two drugs. In our study, duration of fetal exposure to vasopressors is less and required in small dose as we used these drugs only for treatment (not prophylaxis) of hypotension.

In our study there was no statistical difference in APGAR scores at 1 minute and at 5 minute interval which was similar to the study done by Adigun and Amnaor-Boadu. ${ }^{9}$

Atashkhoyi Simin et $\mathrm{al}{ }^{10}$ had showed that there was no significant differences in the umbilical artery values in two groups in the treatment of hypotension after spinal anesthesia in caesarean section.

In Subarachnoid block the rapid onset of sympathetic blockade may result in abrupt, severe hypotension. Maternal hypotension causes decrease in uteroplacental blood flow, impaired fetal oxygenation with asphyxia, fetal acidosis. Hypotension is due to the combined effects of autonomic denervation and the added effect of vagal nerve predominance leading to

1. Peripheral pooling causing decrease in preload.

2. Arteriolar vasodilatation leading to decrease in afterload.

3. Blockade of cardio-accelerator fibers (T1-T4) leading to bradycardia and decrease in contractility further reduces the blood pressure.

Spinal anaesthesia induced hypotension is treated physiologically by

1. Left uterine displacement which is known to decrease the effects of aortocaval compression

2. Improving the venous return so as to increase the preload thereby restoring the cardiac output.

Other mechanical methods like leg elevation (10$15^{\circ}$ ) or leg wrapping with elastocrepe bandages and splints.

In our study, two groups were comparable with respect to demography. The baseline values of mean arterial blood pressure and saturation between the two groups were statistically insignificant. Both groups were similar in the duration of surgery, the total volume of fluid used intra-operatively and the time of spinal to the delivery of the fetus in both the groups.

All of the above studies showed both ephedrine and phenylephrine were equally potent.

\section{Conclusion}

Both the drugs were comparable with respect to the fetal outcome and maternal hemodynamics in patients undergoing elective cesarean section under subarachnoid block.

\section{References}

1. Caruso. J. L, Kirby. R.R. Fluid, Electrolytes, Blood, and Blood substitutes. In: Kirby. R. R, Gravenstein. N, Lobato. E. B, Gravenstein. J. S. Edt: Clinical Anaesthesia Practice, 2nd edition, Philadelphia, W.B. Saunders Company 2002;770-789.

2. Mc Daniel. L. B, Prough. D. S. Fluid therapy during and after anaesthesia. In: Prys-Roberts. C and Brown Jr. B. R. Edt: International practice of Anaesthesia. Oxford, Butterworth- Heinemann 1996, Volume 1/ Chapter 47/ 117.

3. Coe. A.J, Revanas. U.B, Centrallaserettet. K. A. Is Crystalloid preloading useful in spinal anaesthesia in the elderly? Anaesthesia. 1990;45:241-243.

4. Rout C.C, Akoojee S.S, Rocke D.A, Gouws. E. Rapid Administration of Crystalloid Preload does not Decrease the Incidence of Hypotension after Spinal Anaesthesia for Elective Caesarean Section. British J. Anaesth. 1992;68:394-397.

5. Jackson R, Reid J.A, Thorburn J. Volume preloading is not essential to prevent spinal-induced hypotension at Caesarean section. British J. Anaesth. 1995;75:262-265.

6. Lee, A., Ngan Kee, W.D. and Gin, T. (2002) A Quantitative, systematic review of randomized controlled trials of ephedrine versus phenylephrine for the management of hypotension during spinal anesthesia for cesarean deli- very. Anesthesia \& Analgesia, 94, 920926. doi:10.1097/00000539-200204000-00028 
7. Ayorinde B.T, Buczkowski, P, Brown, J, Shah, J. and Buggy, D.J. (2001) Evaluation of pre-emptive intramuscular phenylephrine and ephedrine for reduction of spinal anaesthesia-induced hypotension during caesarean section. British Journal of Anaesthesia. 2001;86:372376.

8. Ngan Kee, W.D., Khaw, K.S., Lau, T.K., Ng, F.F., Chui, K. and Ng, K.L. Randomised double-blinded comparison of phenylephrine vs ephedrine for maintaining blood pressure anaesthesia for non-elective caesarean section. Anaesthesia. 2008;63:1319-1326. doi:10.1111/j.13652044.2008.05635.

9. Adigun TA, Amanor-Boadu SD, Soyannwo SD. Comparison of intravenous ephedrine with phenylephrine for the maintenance of arterial blood pressure during elective caesarean section under spinal anaesthesia. Afr J Med Med Sci. 2010;39:13-20.
10. Atashkhoyi Simin, Fardiazar Zahra, Hatami Marandi Pouya, Torab Reza. In 2012 compared the effectiveness of ephedrine and/or phenylephrine, in treatment of hypotension secondary to spinal anesthesia for cesarean section and their effects on fetal/neonatal outcome. Open Journal of Obstetrics and Gynecology. 2012;2:192-196. doi:10.4236/ojog.2012.23038

How to cite this article: Preethi RA, Pushparani A. Prospective randomized double blinded comparative study on the effects of ephedrine and phenylephrine on fetal outcome and their effects on hypotension during elective cesarean section. Indian J Clin Anaesth. 2018;5(3):321-326. 